\title{
STUDI KLINIK MITRA SEHAT BERWAWASAN KESEHATAN LINGKUNGAN DI DESA PANDAK KECAMATAN BATURRADEN TAHUN 2017
}

\author{
Wahyu Prianingsih *), Lagiono **) \\ Jurusan Kesehatan Lingkungan, Politeknik Kesehatan Kemenkes Semarang, \\ Jl.Raya Baturaden KM 12 Purwokerto, Indonesia
}

\begin{abstract}
Abstrak
Klinik merupakan fasilitas yang memberikan pelayanan kesehatan perorangan dan pelayanan medis dasar atau spesialistik, jika kondisi klinik tidak sesuai dengan persyaratan kesehatan lingkungan akan memungkinkan terjadinya penularan penyakit. Tujuan penelitian ini adalah menjadikan pelayanan kesehatan berwawasan kesehatan lingkungan. Metode penelitian ini adalah analisis deskriptif. Pengumpulan data dilakukan dengan cara wawancara, observasional, pengukuran dan dokumen. Analisis data yang digunakan secara deskriptif dengan menggambarkan kondisi ruang bangunan, penyehatan air bersih, pengelolaan limbah cair dan padat di klinik dari hasil penelitian. Hasil penelitian menunjukkan bahwa kondisi ruang bangunan klinik belum memenuhi syarat yaitu pertemuan lantai dan dinding tidak berbentuk konus, tinggi langit-langit hanya $2,5 \mathrm{~m}$, ruang tindakan umum dan observasi hanya disekat menggunakan tirai, kelembaban ruang khitan $38 \%$ dan ruang poly umum $36 \%$, kebisingan di ruang poly umum 47,67 dBA dan di ruang tunggu 68,20 dBA, luas tempat parkir masih kurang dan tempat sampah belum semuanya memiliki tutup. Penyediaan air bersih di klinik memenuhi syarat dengan debit 0,069 liter/detik, total Coliform 0 per $100 \mathrm{ml}$ sampel, pH 7,0 dan sisa Chlor 0,3 mg/l. Pengelolaan limbah cair di klinik belum memenuhi syarat karena belum memiliki IPAL. Berdasarkan hasil penelitian dapat disimpulkan bahwa Klinik Mitra Sehat belum memenuhi syarat sebagai klinik berwawasan kesehatan lingkungan. Saran bagi pihak klinik yaitu memperbaiki kondisi ruang bangunan sesuai persyaratan dan membangun IPAL untuk mengolah limbah cair yang dihasilkan dari kegiatan klinik.
\end{abstract}

Kata kunci: klinik; kesehatan lingkungan

\begin{abstract}
Study of Mitra Sehat Clinic concept environmental health in Pandak Village, Baturaden in 2017. Clinic is a health service facility and basic medical service or specialistic, if clinic's condition didn't appropriate with the environmenthal health requirements, it will causes probably will be causes of disease transmission. The purpose of this research is to make health service center have a conception about environmenthal health. This research's methods are descriptive analysis. Collecting data by interviewing, observational, measurement, and document. Analyzing data descriptively and illustrating the building's condition, water-healthy process, and the management of liquid waste and solid waste on the clinic from the research result. The research's result shows that the clinic condition isn't appropriate with the requirement. The encounter between the floor and the wall are not konus shaped, the height of the ceiling is 2,5 m, public act room and observation room are separated by just chandelier, the humidity in khitan room is $38 \%$ and in the poly room is $36 \%$, whereas the noises in poly room is $47,67 \mathrm{dBA}$, and in the waiting room is $68,20 \mathrm{dBA}$, the wide of parking area is still not enough and lot of garbage trash didn't have lid. Clean-water provision in clinic is appropriate with requirements that debit is 0,069 liter/second, Coliform 0 in every $100 \mathrm{ml}$ samples, pH 7,0 and Chlor 0,3 $\mathrm{mg} / \mathrm{l}$ the management of liquid waste in the clinic isn't appropriate with requirements yet because of it doesn't have IPAL. From the research result, we can conclude that Mitra Sehat Clinic Center isn't appropriate the requirements of environmenthal health clinic. Advise for the clinic that is to repair the building's room so it is convenient with the requirements and build an IPAL to manage the liquid waste as the result of clinic activity.
\end{abstract}

Keywords: clinic; environmenthal health 


\section{Pendahuluan}

Pembangunan kesehatan bertujuan untuk meningkatkan kesadaran, kemauan dan kemampuan hidup sehat bagi setiap orang agar terwujud derajat kesehatan masyarakat yang setinggi-tingginya. Sesuai dalam UU RI Nomor 36 Tahun 2009 Pasal 46, disebutkan bahwa untuk mewujudkan derajat kesehatan yang setinggi-tingginya bagi masyarakat, diselenggarakan upaya kesehatan yang terpadu dan menyeluruh dalam bentuk upaya kesehatan perseorangan dan upaya kesehatan masyarakat. Upaya kesehatan diselenggarakan dalam bentuk kegiatan dengan pendekatan promotif, preventif, kuratif, dan rehabilitatif yang dilaksanakan secara terpadu, menyeluruh dan berkesinambungan (UU RI Nomor 36 tahun 2009 Pasal 47).

Klinik merupakan fasilitas medis yang lebih kecil dari rumah sakit dan hanya melayani keluhan tertentu serta dikhususkan pada pelayanan kesehatan pasien rawat jalan. Klinik berfungsi sebagai pelayanan kesehatan yang menyelenggarakan kesehatan perorangan dan menyediakan pelayanan medis dasar atau spesialistik (PKFI, 2015). Penyelenggara pelayanan kesehatan tersebut lebih dari satu jenis tenaga kesehatan (perawat atau bidan) dan dipimpin oleh seorang tenaga medis (dokter). Pelayanan kesehatan yang diselenggarakan berupa rawat jalan, one day care dan rawat inap atau home care.

Klinik berdasarkan jenis dapat dibagi ke dalam dua bagian yaitu klinik pratama dan klinik utama. Klinik pratama merupakan klinik yang menyelenggarakan pelayanan medik dasar umum ataupun khusus, sedangkan klinik utama menyelenggarakan pelayanan medik yang spesialistik atau pelayanan medik dasar dan spesialistik. Keberadaan klinik di dalam masyarakat sangat penting karena klinik bisa memberikan fasilitas dan pelayanan kesehatan dengan kualitas yang hampir sama dengan rumah sakit, namun biasanya dengan biaya yang cukup terjangkau. Pelayanan kesehatan klinik yang diberikan harus bermutu, dimana hal ini juga dipengaruhi oleh tersedianya sarana dan prasarana yang mendukung dari setiap kegiatan yang dilakukan.

Klinik dalam menyediakan pelayanan kesehatan harus memenuhi beberapa persyaratan diantaranya yaitu lokasi, ruang dan bangunan serta prasarana yang meliputi instalasi sanitasi, instalasi listrik, pencegahan dan penanggulangan kebakaran, sistem tata udara, sistem pencahayaan dan prasarana lainnya sesuai kebutuhan (Permenkes RI Nomor 9 Tahun 2014). Berdasarkan Kepmeskes RI Nomor 829 Tahun 1999, sarana sanitasi meliputi sarana air bersih, jamban, sarana pembuangan air limbah dan sarana pembuangan sampah.

\footnotetext{
${ }^{*}$ E-mail: wahyuprianingsih@yahoo.com

${ }^{* *}$ E-mail: lagionoabdulwahid@yahoo.co.id
}

Klinik Mitra Sehat merupakan klinik pratama yang menyediakan fasilitas kesehatan tingkat pertama. Klinik Mitra Sehat berlokasi di Jl. Raya Baturraden KM.6, Desa Pandak, Kabupaten Banyumas. Pelayanan kesehatan utama yang ada di klinik yaitu khitan center yang mengkombinasikan khitan dengan hipnotis sebagai salah satu metode khitan unggulan. Kondisi klinik yang tidak sesuai dengan persyaratan kesehatan lingkungan dapat menyebabkan pelayanan kesehatan tidak berjalan optimal dan memungkinkan terjadinya penularan penyakit.

Permasalahan yang akan dikaji yaitu bagaimana cara menjadikan Klinik Mitra Sehat berwawasan kesehatan lingkungan. Tujuan dilakukannya penelitian meliputi: mendeskripsikan kondisi ruang dan bangunan Klinik Mitra Sehat, mendeskripsikan penyediaan air bersih Klinik Mitra Sehat, mendeskripsikan pengelolaan limbah cair Klinik Mitra Sehat, mendeskripsikan pengelolaan limbah padat Klinik Mitra Sehat, dan mendeskripsikan klinik berwawasan kesehatan lingkungan.

\section{Bahan dan Metode}

Penelitian ini merupakan penelitian kualitatif bersifat deskriptif dengan pendekatan evaluasi untuk mewujudkan pelayanan kesehatan berwawasan kesehatan lingkungan.

Lokasi penelitian dilakukan di Klinik Mitra Sehat yang berlokasi di Jl. Raya Baturraden KM.6, Desa Pandak, Kabupaten Banyumas.

Subjek penelitian yaitu ruang dan bangunan serta sarana sanitasi di Klinik Mitra Sehat. Pengukuran yang dilakukan yaitu mengukur sisa chlor dan total koliform pada air bersih, mengukur kualitas fisik udara dan angka kuman pada alat kesehatan.

Instrumen yang digunakan dalam pengumpulan data yaitu : cheklist, kuesioner, thermohygrometer, lux meter, sound level meter, $\mathrm{pH}$ meter, dan uji laboratorium di Laboratorium Kesehatan Masyarakat Kabupaten Banyumas

Analisis data yang digunakan yaitu dengan mendeskripsikan kondisi ruang bangunan klinik, penyehatan air bersih, pengelolaan limbah cair dan padat serta pengelolaan sampah. Hasil pengukuran air bersih yang didapatkan dibandingkan dengan persyaratan yang ada pada Permenkes RI Nomor 416 Tahun 1990 tentang Syarat-Syarat dan Pengawasan Kualitas Air. Hasil pengukuran kondisi ruang bangunan klinik dibandingkan dengan pedoman atau standar Kepmenkes RI Nomor 1204 Tahun 2004 tentang Persyaratan Kesehatan Lingkungan Rumah Sakit.

\section{Hasil dan Pembahasan}

Menurut Peraturan Menteri Kesehatan Republik Indonesia No. 9 Tahun 2014 tentang Klinik bahwa kondisi bangunan klinik sudah memenuhi persyaratan 
yaitu bangunannya bersifat permanen dan fisik bangunannya tidak bergabung dengan tempat tinggal perorangan. Pemeriksaan ruang dan bangunan di Klinik Mitra Sehat dilakukan setiap 1 tahun sekali. Bangunan yang ada di Klinik Mitra Sehat terdiri dari : ruang tunggu, ruang pendaftaran, ruang administrasi, ruang farmasi, ruang kantor, ruang tindakan umum, ruang observasi, ruang poly umum, ruang poly gigi, ruang khitan, ruang ganti, ruang foto, mushola, dan toilet/kamar mandi.

Jumlah ruang yang ada di Klinik Mitra Sehat sudah memenuhi persyaratan sesuai dengan Peraturan Menteri Kesehatan Republik Indonesia No. 9 Tahun 2014 tentang Klinik bahwa bangunan pada klinik pratama paling sedikit terdiri dari : ruang pendaftaran/ruang tunggu, ruang konsultasi, ruang administrasi, ruang obat dan bahan habis pakai untuk klinik yang melaksanakan pelayanan farmasi, ruang tindakan, kamar mandi/wc, dan ruangan lainnya sesuai kebutuhan pelayanan.

Ruang dan bangunan klinik rutin dilakukan pembersihan seperti pembersihan lantai dengan cara dipel dan pembersihan ventilasi udara dengan diVacuum Cleaner. Pembersihan ruangan dilakukan oleh semua karyawan yang ada di klinik karena klinik tidak mempunyai petugas kesehatan lingkungan sehingga kebersihan ruangan menjadi tanggung jawab seluruh karyawan. Alat kebersihan rutin dicek setiap 2-3 bulan sekali. Semua kegiatan yang berhubungan dengan kesehatan lingkungan klinik dapat berjalan lancar dengan biaya operasional kesehatan lingkungan yang terpenuhi.

a. Kondisi ruang dan bangunan klinik yaitu :

1) Lantai

Menurut Kepmenkes RI Nomor 1204 Tahun 2004 tentang Persyaratan Kesehatan Lingkungan Rumah Sakit bahwa lantai yang ada di Klinik Mitra Sehat sudah sesuai dengan persyaratan yaitu lantai kuat/utuh, rata, kondisinya bersih, kedap air, tidak licin dan mudah untuk dibersihkan. Lantai toilet/kamar mandi berbeda dengan lantai di dalam ruangan. Lantai toilet/kamar mandi menggunakan keramik yang tidak licin. Luas lantai dalam setiap ruangan lebih dari $4 \mathrm{~m}^{2} / \mathrm{tt}$. Akan tetapi pertemuan antara lantai dan dinding tidak berbentuk konus/lengkung sehingga sulit untuk dibersihkan dan memungkinkan sebagai tempat berkembangnya bakteri, untuk itu pertemuan antara lantai dan dinding harus berbentuk konus atau lengkung agar mudah dibersihkan pada saat pembersihan lantai, dan debu tidak terselip di sela lantai sehingga lantai terlihat bersih.

2) Dinding

Menurut Kepmenkes RI Nomor 1204 Tahun 2004 tentang Persyaratan Kesehatan Lingkungan Rumah Sakit bahwa dinding yang ada di Klinik Mitra Sehat sudah sesuai dengan persyaratan yaitu dinding bangunan dan ruangan di Klinik Mitra Sehat bersih, rata, berwarna terang dan mudah dibersihkan. Dinding yang sering kontak dengan air juga dibuat kedap air dengan dilapisi keramik setinggi $1,5 \mathrm{~m}$. Kondisi ini harus dipertahankan dan lebih ditingkatkan agar tetap dalam kondisi baik dengan pembersihan rutin dan apabila dinding sudah berwarna kusam sebaiknya dicat ulang.

3) Ventilasi

Tabel 1. Jenis Ventilasi di Klinik Mitra Sehat

\begin{tabular}{clc}
\hline No. & \multicolumn{1}{c}{ Ruangan } & Jenis Ventilasi \\
\hline 1. & Ruang tunggu & Fan \\
2. & Ruang pendaftaran & Fan \\
3. & Ruang administrasi & Fan \\
4. & Ruang farmasi & Fan \\
5. & Ruang kantor & AC \\
6. & Ruang tindakan umum & Fan \\
7. & Ruang observasi & Fan \\
8. & Ruang poly umum & AC \\
9. & Ruang poly gigi & $A C$ \\
10. & Ruang khitan & $A C$ \\
11. & Ruang ganti & Fan \\
12. & Ruang foto & Fan \\
13. & Mushola & Fan \\
14. & Toilet/kamar mandi & Alamiah \\
\hline
\end{tabular}
Menurut Kepmenkes RI Nomor 1204 Tahun 2004 tentang Persyaratan Kesehatan Lingkungan Rumah Sakit bahwa ventilasi yang ada di Klinik Mitra Sehat sudah sesuai dengan persyaratan yaitu ventilasi di Klinik Mitra Sehat menggunakan ventilasi mekanis. Ruang khitan, ruang poly umum, ruang poly gigi, dan ruang kantor menggunakan ventilasi mekanis berupa $A C$, sedangkan ruang lainnya seperti ruang tindakan umum, ruang observasi, ruang tunggu, ruang pendaftaran, ruang administrasi, ruang farmasi, ruang foto, dan ruang ganti menggunakan Fan. Kondisi ini harus dipertahankan dan lebih ditingkatkan yaitu dengan selalu memperhatikan kondisi $A C$ dan Fan agar tetap dalam kondisi baik.

4) Plafon

Menurut Kepmenkes RI Nomor 1204 Tahun 2004 tentang Persyaratan Kesehatan Lingkungan Rumah Sakit bahwa plafon yang ada di Klinik Mitra Sehat sudah sesuai dengan persyaratan yaitu plafon pada semua ruangan memiliki konstruksi yang kuat, berwarna terang dan mudah dibersihkan. Tinggi plafon pada bangunan depan klinik yaitu ruang tunggu lebih dari 2,7 $\mathrm{m}$, tetapi bangunan belakang seperti ruang pendaftaran, ruang farmasi, ruang tindakan umum, ruang observasi, ruang khitan, poly umum dan poly gigi tinggi plafonnya belum memenuhi persyaratan yaitu $2,5 \mathrm{~m}$. Berdasarkan persyaratan Kepmenkes RI Nomor 1204 Tahun 2004 tentang Persyaratan Kesehatan Lingkungan Rumah Sakit, tinggi plafon minimal 2,7 $\mathrm{m}$ dari lantai. Plafon berfungsi untuk membuat ruangan antara yang berguna sebagai penyekat sehingga panas dari atas tidak mudah menjalar kedalam ruangan di bawahnya (Ditjen Cipta Karya, 1997), sehingga plafon yang rendah dapat 
mempengaruhi suhu dan kelembaban di dalam ruangan. Kondisi ini harus diperbaiki dengan cara melakukan perbaikan yaitu plafon dipasang pada ketinggian minimal 2,7 m dari lantai agar udara dan kelembaban di dalam ruangan dapat memenuhi syarat. Ketinggian plafon yang memenuhi persyaratan juga dapat membuat ruangan terkesan lebih luas. Kondisi plafon yang sudah memenuhi syarat harus dipertahankan dan ditingkatkan yaitu dengan cara selalu membersihkan plafon secara rutin agar tetap dalam keadaan bersih.

5) Kontruksi Beranda dan Talang

Menurut Kepmenkes RI Nomor 1204 Tahun 2004 tentang Persyaratan Kesehatan Lingkungan Rumah Sakit bahwa konstruksi beranda dan talang yang ada di Klinik Mitra Sehat sudah sesuai dengan persyaratan yaitu beranda dan talang tidak terdapat genangan air, tidak ada jentik nyamuk dan mudah dibersihkan sehingga tidak menjadi tempat perindukan nyamuk. Kondisi tersebut harus dipertahankan dan lebih ditingkatkan lagi agar tetap dalam kondisi baik dengan cara melakukan pembersihan secara rutin.

6) Pintu

Menurut Kepmenkes RI Nomor 1204 Tahun 2004 tentang Persyaratan Kesehatan Lingkungan Rumah Sakit bahwa pintu yang ada di Klinik Mitra Sehat sudah sesuai dengan persyaratan. Pintu memiliki kontruksi yang kuat dan rapat sehingga dapat mencegah masuknya serangga dan tikus, tetapi ada beberapa ruang yang hanya disekat menggunakan tirai yaitu ruang tindakan umum dan ruang observasi. Ruangan yang tidak berpintu membuat ruang tindakan umum dan ruang observasi lebih bising karena tidak memiliki dinding dan pintu sebagai sekat permanen, selain itu ruang yang hanya terpisah dengan tirai dapat membuat kondisi di dalam ruang tersebut menjadi kurang nyaman. Kondisi ini harus diperbaiki dengan cara melakukan perbaikan yaitu membuat sekat permanen pada ruang tindakan umum dan ruang observasi. Terlebih lagi ruang tersebut memiliki fungsi yang penting yaitu ruang tindakan umum berfungsi untuk pemeriksaan umum dan ruang observasi berfungsi untuk menangani pasien dengan kondisi khusus. Sekat permanen pada ruangan dapat mengurangi kebisingan di dalam ruangan. Kondisi pintu yang sudah memenuhi persyaratan harus dipertahankan dan lebih ditingkatkan lagi dengan cara segera memperbaiki pintu apabila ada kerusakan.

7) Intensitas Cahaya

Tabel 2. Hasil Pengukuran Intensitas Cahaya di Klinik Mitra Sehat

\begin{tabular}{ccc}
\hline No. & \multicolumn{1}{c}{ Ruangan } & Intensitas Cahaya (Lux) \\
\hline 1. & Ruang tunggu & 120 \\
2. & Ruang poly umum & 130 \\
3. & Ruang khitan & 980 (di bawah lampu \\
sorot)
\end{tabular}

Sakit bahwa intensitas cahaya di ruang tunggu dan ruang poly umum sudah memenuhi syarat. Intensitas cahaya di ruang tunggu yaitu 120 lux dan di ruang poly umum 130 lux sesuai dengan Kepmenkes RI Nomor 1204 Tahun 2004 standarnya yaitu 100-300 lux. Intensitas cahaya di ruang khitan yaitu 980 lux dengan pengukuran di bawah lampu sorot. Kondisi tersebut harus dipertahankan agar intensitas cahaya sesuai dengan persyaratan dengan cara melakukan pengukuran secara rutin.

8) Suhu

Tabel 3. Hasil Pengukuran Suhu di Klinik Mitra Sehat

\begin{tabular}{|c|c|c|}
\hline No. & Ruangan & Suhu $\left({ }^{0} \mathrm{C}\right)$ \\
\hline 1. & Ruang tunggu & 22 \\
\hline 2. & Ruang poly umum & 23 \\
\hline & Ruang khitan & 22 \\
\hline
\end{tabular}

2004 tentang Persyaratan Kesehatan Lingkungan Rumah Sakit bahwa suhu yang di Klinik Mitra Sehat sudah sesuai dengan persyaratan yaitu suhu di ruang tunggu $22^{\circ} \mathrm{C}$, ruang poly umum $23^{\circ} \mathrm{C}$ dan ruang khitan $22^{\circ} \mathrm{C}$. Berdasarkan persyaratan suhu standar yaitu $22^{\circ} \mathrm{C}-24^{\circ} \mathrm{C}$ dengan $A C$ atau suhu kamar tanpa $A C$. Kondisi tersebut harus dipertahankan agar suhu ruangan tetap terjaga.

9) Kelembaban

Tabel 4. Hasil Pengukuran Kelembaban di Klinik Mitra Sehat

\begin{tabular}{clc}
\hline No. & \multicolumn{1}{c}{ Ruangan } & Kelembaban (\%) \\
\hline 1. & Ruang tunggu & 45 \\
2. & Ruang poly umum & 36 \\
3. & Ruang khitan & 38 \\
\hline
\end{tabular}

Menurut Kepmenkes RI Nomor 1204 Tahun

2004 tentang Persyaratan Kesehatan Lingkungan Rumah Sakit bahwa kelembaban di ruang tunggu sudah memenuhi syarat yaitu $45 \%$ sedangkan di ruang poly umum dan ruang khitan belum memenuhi syarat yaitu di poly umum $36 \%$ dan di ruang khitan 38\%. Persyaratan kelembaban berdasarkan Kepmenkes RI Nomor 1204 Tahun 2004 tentang Persyaratan Kesehatan Lingkungan Rumah Sakit yaitu 45-60\%. Kondisi tersebut harus ditingkatkan lagi agar kelembaban ruangan memenuhi persyaratan. Kelembaban yang rendah akan membuat ruangan menjadi kurang nyaman. Kelembaban ruangan yang rendah bisa disebabkan karena kodisi pendingin ruangan yang kotor, ketinggian langit-langit yang kurang dari 2,7 $\mathrm{m}$ dan suhu/cuaca di luar ruangan. Kelembaban dapat ditingkatkan dengan cara membuat ketinggian langit-langit lebih dari 2,7 m, meletakan tanaman hias di dalam ruangan atau dengan cara menggunakan humidifier.

10) Intensitas Suara

Tabel 5. Hasil Pengukuran Intensitas Suara di Klinik Mitra Sehat

\begin{tabular}{ccc}
\hline No. & Ruangan & Intensitas Suara $(\mathrm{dBA})$ \\
\hline 1. & Ruang tunggu & 68,20 \\
2. & Ruang poly umum & 47,67 \\
\hline
\end{tabular}




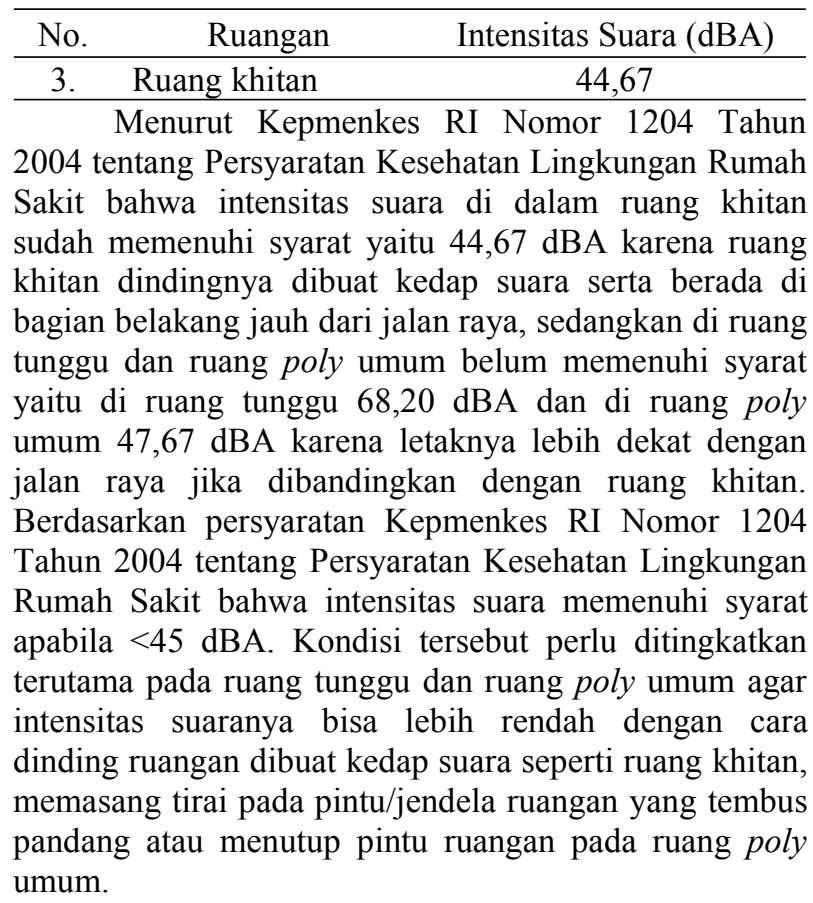

11) Halaman Taman dan Tempat Parkir

Menurut Kepmenkes RI Nomor 1204 Tahun 2004 tentang Persyaratan Kesehatan Lingkungan Rumah Sakit bahwa tempat parkir di Klinik Mitra Sehat sudah sesuai dengan persyaratan yaitu bersih dan tidak berdebu/becek karena sudah diplester. Halaman tempat parkir terpisah antara mobil dan motor yang ditandai dengan garis parkir sehingga mampu menampung mobil dan motor karyawan/pengunjung. Halaman juga dilengkapi dengan tempat sampah yang cukup dan terpisah antara sampah organik dan anorganik tetapi tempat sampah yang ada di halaman belum memiliki tutup.

Tempat parkir yang ada di Klinik Mitra Sehat memiliki luas $104 \mathrm{~m}^{2}$. Tempat parkir yang ada di klinik cukup untuk menampung kendaraan pada saat tidak ada pasien khitan, tetapi apabila terdapat pasien khitan tempat parkir kurang luas sehingga ada kendaraan pengunjung khususnya khitan yang diparkir di tepi jalan karena halaman parkir penuh. Kondisi tersebut harus diperbaiki dengan cara halaman parkir sebaiknya dibuat lebih luas agar dapat menampung seluruh kendaraan pasien/pengunjung. Tempat sampah yang belum memiliki tutup sebaiknya diberi tutup agar tidak menjadi tempat berkembang biaknya lalat dan mencegah bau.

12) Saluran Air Limbah

Menurut Kepmenkes RI Nomor 1204 Tahun 2004 tentang Persyaratan Kesehatan Lingkungan Rumah Sakit bahwa saluran air limbah di Klinik Mitra Sehat sudah sesuai dengan persyaratan yaitu saluran air limbah dibuat tertutup dan alirannya lancar. Saluran drainase dapat mengalir lancar dan disalurkan ke parit yang berada di depan klinik. Kondisi tersebut harus dipertahankan dan ditingkatkan lagi dengan cara melakukan pemantauan secara berkala agar apabila terjadi kebocoran atau kerusakan pada saluran air limbah dapat langsung diperbaiki. Saluran drainase juga harus dilakukan pemantauan secara berkala sehingga apabila terjadi penyumbatan dapat langsung diperbaiki agar tetap mengalir lancar.

13) Toilet dan Kamar Mandi

Menurut Kepmenkes RI Nomor 1204 Tahun 2004 tentang Persyaratan Kesehatan Lingkungan Rumah Sakit bahwa toilet/kamar mandi yang ada di Klinik Mitra Sehat sudah sesuai dengan persyaratan yaitu toliet/kamar mandi berjumlah 4 dan tempat tidur yang ada berjumlah 6 buah. Sesuai dengan Kepmenkes RI Nomor 1204 Tahun 2004 tentang Persyaratan Kesehatan Lingkungan Rumah Sakit, rasio toilet/kamar mandi dengan tempat tidur $1: 10$. Semua toilet/kamar mandi memiliki lubang penghawaan yang berhubungan langsung dengan udara luar. Kamar mandi dan toilet untuk pria, wanita dan karyawan juga terpisah satu sama lain. Jumlah toilet yang ada sudah mencukupi kebutuhan terutama pada toilet pengunjung, tetapi saluran pembuangan air limbahnya tidak dilengkapi dengan penahan bau (water seal), untuk itu perlu ditingkatkan lagi dengan cara memasang water seal pada saluran pembuangan air limbah agar toilet/kamar mandi tidak bau.

14) Alat Kesehatan

Alat kesehatan yang digunakan di Klinik Mitra Sehat untuk melakukan proses khitan yaitu minor set yang terdiri dari berbagai jenis gunting dan pinset. Klinik Mitra Sehat memiliki 12 set minor yang digunakan untuk proses khitan. Setiap alat setelah digunakan akan langsung didesinfeksi. Proses desinfeksi dilakukan setiap kali pemakaian alat dengan menggunakan bahan kimia yaitu byclin yang kemudian diusap dengan alkohol. Proses desinfeksi dilakukan oleh setiap pemakai alat dan proses desinfeksi dilakukan di wastafel yang sudah tersedia disetiap ruangan. Alat yang telah didesinfeksi disimpan di dalam almari steril. Hasil pemeriksaan bakteriologis dari sampel usap alat kesehatan didapatkan hasil jumlah koloni kuman yaitu 0 $\mathrm{CFU} / \mathrm{cm}^{2}$. Hasil pemeriksaan sudah memenuhi syarat yaitu alat kesehatan yang telah didesinfeksi jumlah koloni kuman harus $0 \mathrm{CFU} / \mathrm{cm}^{2}$. Kondisi tersebut harus dipertahankan karena cara dan proses desinfeksi sudah benar sehingga alat kesehatan sudah tidak terdapat kuman.

15) Linen

Klinik Mitra Sehat dalam memberikan pelayanan kesehatan setiap harinya menghasilkan linen kotor seperti sprei dan perlak. Linen kotor dibersihkan dengan cara didesinfeksi setiap hari bahkan dalam satu hari bisa dilakukan dua kali proses pencucian apabila terdapat banyak pasien khitan. Linen yang ada di klinik diganti setiap satu kali pemakaian. Setiap hari klinik menyediakan 100 set linen bersih yang siap digunakan. 
Proses pencucian linen kotor dilakukan di klinik menggunakan mesin cuci. Pencucian linen menggunakan desinfektan berupa byclin. Linen yang sudah dicuci dan didesinfektan kemudian dikeringkan. Linen perlak dikeringkan dengan cara dijemur di bawah matahari. Linen yang telah kering disimpan di dalam almari steril. Proses khitan dilakukan oleh 3 orang tenaga medis pada setiap tim dari jumlah keseluruhan ada 3 tim medis. Sarung tangan yang digunakan oleh tim medis saat melakukan proses khitan digunakan satu kali pemakaian. Sarung tangan yang digunakan menggunakan sarung tangan karet yang tipis khusus untuk satu kali pemakaian.

16) Ruangan Klinik Mitra Sehat

Ruangan yang ada di klinik dibersihkan dengan cara didesinfeksi setiap satu minggu sekali yaitu pada hari Minggu. Proses desinfeksi yang pertama yaitu menyemprotkan bahan kimia pengusir nyamuk dan selanjutnya ruangan disemprot menggunakan bahan kimia khusus untuk desinfeksi ruangan.

b. Penyediaan Air Bersih di Klinik Mitra Sehat

Menurut Kepmenkes RI Nomor 1204 Tahun 2004 tentang Persyaratan Kesehatan Lingkungan Rumah Sakit bahwa air bersih di Klinik Mitra Sehat sudah memenuhi persyaratan. Kuantitas air bersih yang tersedia $>500 \mathrm{lt} / \mathrm{hr}$ dan tersedia air minum sesuai dengan kebutuhan pada setiap tempat kegiatan. Air bersih yang tersedia menggunakan air dari sumber PDAM dengan debit 0,069 liter/detik sedangkan untuk air minum menggunakan air galon isi ulang.

Kualitas air bersih secara bakteriologis dengan pengukuran total Coliform sudah memenuhi syarat dengan hasil 0 per $100 \mathrm{ml}$ sampel. Berdasarkan Permenkes No. 416 Tahun 1990 tentang Syarat-syarat dan Pengawasan Kualitas Air, kadar maksimum total bakteri Coliform pada air bersih dengan perpipaan yaitu 10 per $100 \mathrm{ml}$ sampel. Secara kimia dengan pengkuran $\mathrm{pH}$ dan sisa Chlor juga memenuhi syarat dengan hasil pH 7,0 dan sisa Chlor 0,3 mg/l. Berdasarkan Permenkes No. 416 Tahun 1990 tentang Syarat-syarat dan Pengawasan Kualitas Air, pH pada air bersih berkisar antara 6,5 - 9,0. Menurut Suparmin (2011, h.14) sisa Chlor dalam air sebaiknya dijaga dengan konsentrasi 0,2 $\mathrm{mg} /$ liter - 0,5 mg/liter. Air bersih yang bersumber dari PDAM dalam pendistribusiannya tidak bocor dan ditampung dalam tempat tertutup.

Air bersih yang ada di klinik rutin dilakukan pemeriksaan setiap 1 tahun sekali. Pemeriksaan yang dilakukan yaitu pemeriksaan fisik, kimia dan bakteriologis tetapi pihak klinik tidak pernah tahu apakah hasilnya memenuhi persyaratan atau tidak karena hasil pemeriksaan tidak pernah diterima pihak klinik. Kondisi tersebut berdasarkan hasil pemeriksaan sebaiknya harus dipertahankan karena sudah memenuhi persyaratan dan untuk hasil pemeriksaan yang tidak pernah diterima sebaiknya lebih diperhatikan lagi dengan cara meminta hasil pemeriksaan setiap kali dilakukan pengambilan sampel air bersih sehingga klinik akan mengetahui hasil pemeriksaannya.

c. Pengelolaan Limbah Cair di Klinik Mitra Sehat

Menurut Kepmenkes RI Nomor 1204 Tahun 2004 tentang Persyaratan Kesehatan Lingkungan Rumah Sakit belum memenuhi persyaratan. Limbah cair yang dihasilkan di Klinik Mitra Sehat tidak dilakukan pengolahan karena belum memiliki IPAL. Limbah cair yang dihasilkan akan disalurkan ke septiktank melalui saluran yang tertutup dan kedap air. Limbah cair yang dihasilkan berasal dari limbah toilet/kamar mandi, pencucian alat kesehatan dan limbah dari wastafel yang kemudian disalurkan ke septiktank dan diresapkan ke tanah. Kondisi tersebut belum memenuhi persyaratan karena belum ada pengolahan terlebih dahulu sehingga memungkinkan terjadinya pencemaran tanah, untuk itu perlu dilakukan pengolahan terlebih dahulu dengan menggunakan IPAL sebelum diresapkan ke tanah/dialirkan ke badan air sehingga air limbah lebih aman bagi lingkungan.

d. Pengelolaan Limbah Padat di Klinik Mitra Sehat

Menurut Kepmenkes RI Nomor 1204 Tahun 2004 tentang Persyaratan Kesehatan Lingkungan Rumah Sakit sudah memenuhi persyaratan. Limbah padat yang dihasilkan di Klinik Mitra Sehat sudah terpisah antara limbah padat medis dan non medis. Limbah non medis yang dihasilkan juga sudah terpisah antara organik dan anorganik. Tempat sampah yang digunakan untuk menampung limbah padat medis maupun non medis terbuat dari bahan yang kuat, tahan karat, kedap air, dilapisi kantong plastik selain itu juga tempat sampah sudah dilengkapi dengan simbol antara sampah medis dan non medis. Tempat sampah non medis dilapisi kantong plastik berwarna hitam dan tempat sampah medis dilapisi kantong plasting berwarna kuning. Limbah medis juga ditampung dalam safety box khususnya limbah benda tajam seperti jarum suntik.

Penampungan limbah medis sudah sesuai persyaratan berdasarkan Kepmenkes RI Nomor 1204 Tahun 2004 tentang Persyaratan Kesehatan Lingkungan Rumah Sakit yaitu limbah infeksius, patologi dan anatomi dimasukkan dalam kontainer/kantong plastik berwarna kuning. Tempat sampah yang ada di dalam ruangan sudah tertutup tetapi untuk ruang tunggu dan halaman tempat sampahnya belum tertutup. Sebaiknya semua tempat sampah diberi tutup agar tidak menimbulkan bau dan tidak menjadi tempat berkembang biaknya lalat yang dapat menjadi vektor penyakit. Jumlah tempat sampah yang ada yaitu 16 buah yang terletak di halaman parkir 4 buah dan sisanya tersebar diseluruh ruangan. Limbah non medis yang sudah terkumpul diangkut ke TPA satu hari sekali sedangkan untuk limbah medis akan diangkut 1 atau 2 minggu sekali oleh pihak ke tiga karena klinik sudah memiliki MoU dengan Java Medivest. Sebelum diangkut ke Java 
Medifest sampah medis disimpan di gudang yang tersedia di klinik. Sampah medis disimpan di dalam plastik khusus dengan warna kuning yang digunakan untuk melapisi tempat sampah medis.

e. Klinik Berwawasan Kesehatan Lingkungan

Klinik Mitra Sehat dapat dikatakan berwawasan kesehatan lingkungan apabila memenuhi persyaratan kesehatan lingkungan seperti penyehatan ruang bangunan dan terpenuhinya sarana sanitasi yang memenuhi syarat. Penyehatan ruang bangunan di Klinik Mitra Sehat belum memenuhi syarat secara keseluruhan karena pertemuan lantai dan dinding tidak berbentuk konus sehingga sulit dibersihkan, saluran pembuangan air limbah tidak dilengkapi dengan penahan bau (water seal), tinggi langit-langit pada bangunan belakang klinik kurang dari $2,7 \mathrm{~m}$ yaitu hanya $2,5 \mathrm{~m}$, ruang tindakan umum dan ruang observasi hanya disekat menggunakan tirai.

Kelembaban ruangan belum memenuhi syarat terutama pada ruang poly umum dan khitan yaitu berkisar 36-38 \%. Kebisingan di ruang poly umum dan ruang tunggu masih melebihi batas yaitu di ruang poly umum 47,67 dBA dan di ruang tunggu 68,20 dBA. Luas tempat parkir masih kurang apabila digunakan untuk menampung kendaraan pada saat ada pasien khitan. Sarana sanitasi di Klinik Mitra Sehat belum memiliki IPAL sehingga limbah cair yang dihasilkan belum dilakukan pengolahan. Tempat sampah yang ada di klinik belum semuanya memiliki tutup tertuma tempat sampah yang ada di ruang tunggu dan halaman depan.

Klinik Mitra Sehat dapat menjadi klinik berwawasan kesehatan lingkungan dengan memperbaiki kondisi ruang bangunan yaitu pertemuan lantai dan dinding dibuat konus sehingga mudah dibersihkan, saluran pembuangan air limbah dilengkapi dengan penahan bau (water seal), langit-langit dibuat dengan ketinggian minimal 2,7 $\mathrm{m}$ dari lantai, membuat sekat permanen pada ruang tindakan umum dan ruang observasi seperti dengan menggunakan dinding dan pintu.

Kelembaban ruangan harus dinaikkan menjadi 45-60 \% dan kebisingan diturunkan menjadi $<45$ dBA. Kelembaban ruangan dapat bertambah dengan cara membuat ketinggian langit-langit minimal $2,7 \mathrm{~m}$, menempatkan beberapa tanaman hias di dalam ruangan atau memasang humidifier di dalam ruangan. Tanam hias yang dapat bertahan di dalam ruang ber-AC sperti bunga krisan, sirih gading, bunga lily, Aloe vera dan kaktus bunga. Kebisingan ruangan dapat diturunkan dengan cara memasang alat penahan suara pada dinding ruangan, memasang tirai pada jendela/pintu yang tembus pandang atau menutup pintu ruangan. Tempat parkir yang ada sebaiknya diperluas agar mampu menampung semua kendaraan pasien/pengunjung. Sarana santasi di klinik juga harus dilengkapi dengan cara membangun IPAL sederhana untuk mengolah limbah cair yang dihasilkan dari kegiatan di dalam klinik sehingga limbah menjadi ramah lingkungan dan tempat sampah diberi tutup agar tidak menimbulkan bau dan tidak menjadi tempat berkembang biaknya lalat yang dapat menjadi vektor penyakit.

\section{Kesimpulan}

Hasil dan pembahasan tentang kondisi Klinik Mitra Sehat dapat diambil simpulan bahwa kondisi ruang bangunan Klinik Mitra Sehat seperti ruang tunggu, ruang kantor, ruang foto, mushola dan toilet/kamar mandi sudah memenuhi syarat, sedangkan ruang pendaftaran, ruang administrasi, ruang farmasi, ruang tindakan umum, ruang observasi, poly umum, poly gigi, ruang khitan, dan ruang ganti belum memenuhi persyaratan sesuai dengan Keputusan Menteri Kesehatan RI Nomor 1204 Tahun 2004 tentang Persyaratan Kesehatan Lingkungan Rumah Sakit. Penyediaan air bersih di Klinik Mitra Sehat sudah sesuai dengan Keputusan Menteri Kesehatan RI Nomor 1204 Tahun 2004 tentang Persyaratan Kesehatan Lingkungan Rumah Sakit. Pengelolaan limbah cair di Klinik Mitra Sehat belum sesuai dengan Keputusan Menteri Kesehatan RI Nomor 1204 Tahun 2004 tentang Persyaratan Kesehatan Lingkungan Rumah Sakit. Pengelolaan limbah padat di Klinik Mitra Sehat sudah sesuai dengan Keputusan Menteri Kesehatan RI Nomor 1204 Tahun 2004 tentang Persyaratan Kesehatan Lingkungan Rumah Sakit. Klinik Mitra Sehat belum memenuhi syarat sebagai klinik berwawasan kesehatan lingkungan.

Klinik Mitra Sehat dapat menjadi klinik berwawasan kesehatan lingkungan, penulis memberikan saran yaitu perlu adanya perbaikan pada ruang bangunan klinik. Plafon pada bangunan belakang harus dibuat dengan ketinggian minimal 2,7 m. Perlu adanya perbaikan dengan memberikan sekat permanen pada ruang tindakan umum dan ruang observasi. Kelembaban di ruang khitan dan poly umum harus dinaikkan. Intensitas suara di ruang tunggu dan ruang poly umum harus diturunkan. Tempat parkir harus diperluas. Tempat sampah yang ada di klinik harus memiliki tutup. Perlu dibuat IPAL untuk pengolahan limbah cair yang dihasilkan dari kegiatan klinik.

\section{Daftar Pustaka}

Bekker, J. G., Craig, I. K., \& Pistorius, P. C. (1999). Modeling and Simulation of Arc Furnace Process. ISIJ International, 39(1), 23-32.

Dinas Kesehatan Klaten, 2015, Manajemen Kesehatan Lingkungan Puskesmas, at http://dinkesklatenkab.com/klaten-utara/articles/d etail/Manajemen-kesehatan-lingkungan-Puskesm as (diakses pada tanggal 22 Februari 2017 pukul 17:38 AM)

Hanifah Shalihah, 2016, Suhu dan Kelembaban, at https://www.academia.edu/Bookmarks (diakses 
pada tanggal 14 Juni 2017 pukul 15:14 AM)

Indonesia, 1992, Undang-Undang Republik Indonesia Nomor 23 Tahun 1992 Tentang Kesehatan, Jakarta

Indonesia, 2009, Undang-undang Republik Indonesia Nomor 36 Tahun 2009 Tentang Kesehatan, Jakarta

Indonesia, 2014, Peraturan Pemerintah Republik Indonesia Nomor 66 Tahun 2014 Tentang Kesehatan Lingkungan, Jakarta

Ita Yunita, 2013, Studi Penyediaan Air Bersih di Rumah Sakit Umum Daerah Dr. M. Ashari Pemalang Tahun 2013, Skripsi, Purwokerto: Kementerian Kesehatan RI Politeknik Kesehatan Semarang Jurusan Kesehatan Lingkungan

Kepmeskes RI, 1999, Keputusan Menteri Kesehatan Republik Indonesia Nomor 829 Tahun 1999 tentang Persyaratan Kesehatan Rumah Tinggal, Jakarta

Kepmenkes RI, 2004, Keputusan Menteri Kesehatan Republik Indonesia Nomor 1204/MENKES/SK/X/2004 Tentang Persyaratan Kesehatan Lingkungan Rumah Sakit, Jakarta

Perda, 2004, Peraturan Daerah Provinsi Jawa Tengah Nomor 5 Tahun 2012 Tentang Perubahan Atas Peraturan Daerah Provinsi Jawa Tengah Nomor 10 Tahun 2004 Tentang Baku Mutu Air Limbah, Jawa Tengah
Permenkes RI, 1990, Peraturan Menteri Kesehatan Republik Indonesia Nomor 416 Tahun 1990 tentang Syarat-Syarat dan Pengawasan Kualitas Air, Jakarta

Permenkes RI, 2014, Peraturan Menteri Kesehatan Republik Indonesia Nomor 9 Tahun 2014 tentang Klinik, Jakarta

PP RI, 2008, Peraturan Pemerintah Republik Indonesia Nomor 42 Tahun 2008 tentang Pengelolaan Sumber Daya Air, Jakarta

Risma Suryani Prasetyaningsih, 2016, Studi Kondisi Kesehatan Lingkungan RSUD Prof. Dr. Margono Soekarjo Purwokerto Tahun 2016, Skripsi, Purwokerto: Kementerian Kesehatan RI Politeknik Kesehatan Semarang Jurusan Kesehatan Lingkungan

Suparmin, 2011, Teori dan Praktik Pengolahan Air Minum, Purwokerto: Yayasan Sanitarian Banyumas

Tiffani Rhapsody Lila, 2015, Tinjauan Kondisi Kesehatan Lingkungan RSUD Kardinah Tegal Tahun 2015, Skripsi, Purwokerto: Kementerian Kesehatan RI Politeknik Kesehatan Semarang Jurusan Kesehatan Lingkungan

Tri Cahyono, 2014, Pedoman Penulisan Proposal Penelitian dan Karya Tulis Ilmiah / Skripsi, Purwokerto: Kementerian Kesehatan RI Politeknik Kesehatan Kemenkes Semarang Jurusan Kesehatan Lingkungan 